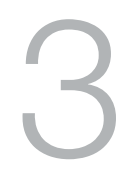

\title{
Population ageing in Australia- National policy challenges and future directions
}

\author{
John Piggott
}

Population ageing comprises two related but distinct forces: the ageing of the baby boomer generation, and related policy challenges around retirement support, health care, aged care, and the management of intergenerational relationships; and the impacts of population dynamics and evolving changes in demographic structure, nationally, regionally and globally. The first is generally given more attention, for understandable reasons - the policy challenges are very direct and relatively near-term. In particular, retirement and retirement financing, health and ageing, and aged care are all important national priorities, requiring evidence-based changes in policy formulation, business practice, and family behaviour.

But the longer-term influences of shifting population dynamics may eventually have the more profound impact on Australians. I have in mind here the impact of generational imbalance on intergenerational solidarity, on taxation policy, on the structure of our labour force, and the impact of changing population structures within our major trading partners on demand for our trade, our investment, and migration. 
These two aspects of population ageing are related not just because demographic change will evolve steadily and inexorably for at least the next generation. They are also linked through national response: what we do about an ageing demographic will profoundly impact the longer-term outcomes of population dynamics. The issue becomes even more complex because population dynamics internationally, but especially in Asia, will likely impact the Australian demographic transition and its economic and social correlates, through migration, sources of international investment, trade patterns, and ultimately the global level of economic activity.

While Australia, in common with most of the world's nations, is ageing by most agreed measures, such as dependency ratio or median age, average remaining life expectancy is also increasing. Intergenerational dynamics are much more complex than the simple arithmetic used in measuring the traditional dependency ratio, the population over some arbitrary age, often 65 , divided by the population aged between 15 and 64. For policymakers, dependency lies at the heart of the issue, because, unless self-provision has been mandated, and/or family support is forthcoming, providing adequate services for those whose human capital has been mostly depleted requires taking resources from elsewhere, which in most cases means younger workers. Higher taxes and more informal resource commitment are the inevitable consequences of an ageing demographic, although alternative measures of dependency project differing impressions of the nature, timing and extent of this process. For example, a calculation of dependency ratios that holds constant remaining life expectancy as the cut-off for switching to 'dependant' status, rather than chronological age, generates dependency ratios that decline for some significant period before rising again (Spijker and MacInnes 2013). On the other hand, using National Transfer Accounts (NTA), of the type generated by Peter McDonald and his team for Australia (Rice et al. 2014), gives the opposite result (Prskawetz and Sambt 2014).

In what follows, much is speculative. I will first make some remarks about the challenges and opportunities generated by the ageing of the baby boomers, focusing especially on retirement incomes, and health and aged care, but also touching on housing and risk. I then take up the question of demographic dynamics, both domestic and international, and their impact on Australia's future. 


\section{The challenges of an ageing demographic}

There seems little doubt that an ageing population will lead to greater public sector support, simply because government, in its role as insurer of last resort, will be called upon more and more to cover the risks to which older people with depleted earning capacity are exposed. In an OECD background paper prepared by Ed Whitehouse and myself for a meeting of Ministers of Social Security in 2011 (Piggott and Whitehouse 2011), we reported projections for a range of countries of outlays on pensions, health and long-term care, comparing 2010 and 2050. I reproduce Figure 1 from that paper here. In all these countries, outlays are projected to rise significantly, with the proportionate increase greatest for those countries, such as Korea, with the most rapidly ageing projections. Australia, along with demographically and economically similar countries such as Canada, registered about a 30 per cent increase, from 10 per cent to about 13 per cent of GDP. While these calculations are now a few years old, their import remains clear.

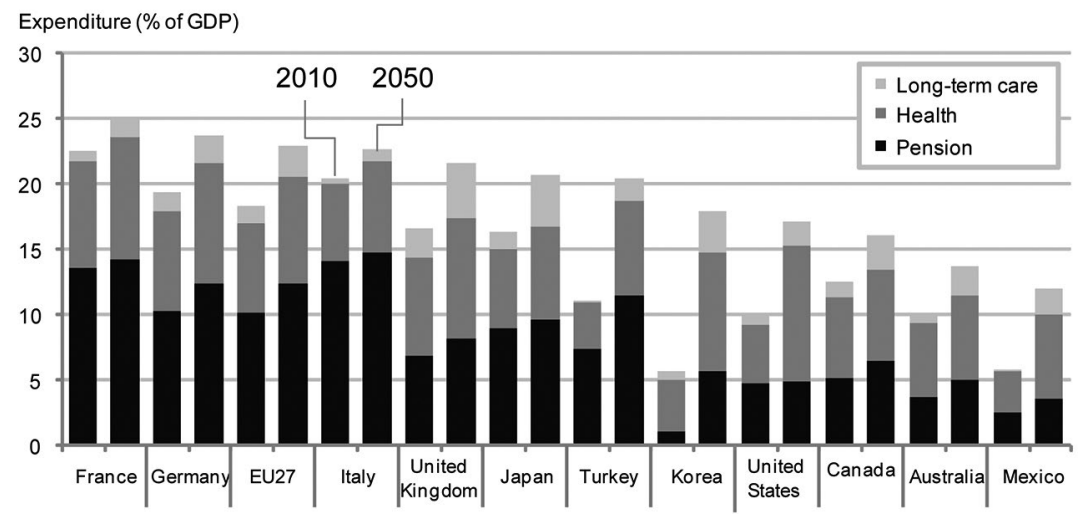

Figure 1. Fiscal costs of ageing populations (projected pension, health and long-term care expenditures, 2010 and 2050, per cent of GDP)

Source: OECD (2011), Pensions at a Glance: Retirement-Income Systems in OECD and G-20 Countries; OECD (2011), Help Wanted? Providing and Paying for Long-Term Care; European Commission (2009), 'The 2009 Ageing Report: Economic and Budgetary Projections for the EU 27 Member States (2008-2060)', European Economy, No. 2/2009, Brussels; International Monetary Fund (2009), 'Fiscal Implications of the Global Economic and Financial Crisis', Staff Position Note No. 09/13, Washington, DC; Standard \& Poor's (2010), 'Global Aging 2010: An Irreversible Truth'. 


\section{Retirement and retirement incomes ${ }^{1}$}

Australia is, on the whole, well served by the existing framework of retirement policy. While many questions remain unanswered, and there is much room for improvement, the current system is sustainable, has a high degree of integrity, and will, once the superannuation guarantee becomes mature, provide adequate resources in retirement.

It is useful to think of our retirement income structure in terms of the three-pillar framework adopted by the OECD. The first pillar operates as a non-contributory transfer, which means it is potentially available to all. ${ }^{2}$ This is represented in Australia by the Age Pension. The second pillar offers payments related to pre-retirement labour income, on some mandatory basis (in Australia, the Superannuation Guarantee). Typically, this is based on contributions computed as some proportion of wages or salary, paid either by employer, employee, or both. The third pillar comprises voluntary retirement saving, typically taxpreferred.

Focusing on the first two pillars allows us to loosely link the instruments of policy to targets. The first pillar is designed to alleviate poverty, while the second pillar aims to encourage consumption smoothing between working and retirement life. Because the Age Pension is non-contributory, and the value of the maximum single benefit has recently been increased from 25 per cent to 27.8 per cent of average earnings, it does a remarkably good job of ameliorating poverty among the elderly. If, like the US, we set the poverty line at 40 per cent of median income, then the elderly poverty rate is only 5 per cent (Chomik and Piggott 2014). Further, even when poverty is set at the OECD level, taking account of housing reduces elderly poverty to 13.5 per cent (Yates and Bradbury 2010). The calculation of high poverty rates reported by, for example, the OECD misses two important points. First, most households with a head aged 65 or more

1 This material draws in part on my 2013 ASSA Hancock Lecture, www.youtube.com/ watch?v=lb6Uv4kIGfU. My views have also benefited from many discussions with my colleague Cagri Kumru.

2 It may only be available subject to a means test, since its function is to ensure the elderly are adequately provided for. 
own a home outright. ${ }^{3}$ Second, the gap between the poverty line (set at 50 per cent of median household equivalised income) and the value of the full Age Pension is quite small.

When we turn to incentives, conventional economic wisdom emphasises the disincentive impacts of high effective marginal tax rates (EMTRs). But the overall economic impact of means testing is poorly understood, and is an important topic for further research. Here, we simply note three caveats to the presumption that means testing a social pension induces net perverse disincentives. First, like any other tax-financed financial transfer, retirement income transfers impact on incentives at two points in economic transactions: when the tax is levied, and when the transfer is received. These two points of price distortion need to be considered together in assessing the overall incentive impact of means testing. As the taper rate (and the associated EMTR) is reduced, the overall revenue requirement of the program will increase, and this will require higher tax rates to be applied to others in the economy, probably workers. If they already pay high taxes, as in developed countries, then the same argument about disproportionate efficiency costs of high marginal tax rates will apply, offsetting the EMTR reduction among pension recipients.

Second, while a means-tested pension will impose high EMTRs on those at the margin of eligibility, where withdrawal of the pension is operative, many individuals potentially impacted by a universal pension will be unaffected by a targeted pension, whereas their behaviour would be impacted by a demogrant. For a given full pension value, steeper tapers will reduce the number of consumers affected by the social pension overall. It seems plausible that the group excluded by a steeper taper is likely on average to have more possibilities of behaviour modification than less well-off groups in the community.

Third, recent analysis (for example, Conesa et al. 2009) suggests that a tax on capital income may have efficiency-enhancing properties in an economy where there are restrictions on age-based taxes, and where liquidity constraints prevail. A means test is an age-based tax on capital income, and more precisely, a tax on retirement capital (Kumru

3 Those Age Pension recipients who rent receive rental assistance, which goes some way to making up the shortfall from the absence of principal residence. 
and Piggott 2010). In more recent research with economy-wide models capturing these points, it is frequently found that steeper tapers may be efficiency-preferred.

The current Australian discussion around steeper tapers is therefore one that the recent economics literature supports, if at this stage only in a preliminary way (Sefton et al. 2008; Kumru and Piggott 2009). There is a major research agenda around means testing just getting underway.

A final point on means-testing structures relates to the inclusion of earned income in the means test. Many countries with conventional social security have an 'earnings test', which effectively operates as a means test on earned income, while ignoring capital resources. Recent analysis (Hernaes et al. 2016) suggests that relaxing the 'earnings test' on social security, which in the context of a social pension such as Australia's can be interpreted as relaxing the means test on earned income, may lead to improved mature labour force participation. As we will see below, this is perhaps the most important family and market adjustment available to respond to the pressures of an ageing demographic, and a major policy challenge is to ensure as far as possible that policy structures and settings encourage rather than impede working longer.

When it comes to income replacement or consumption smoothing, however, the picture is less sanguine. The Superannuation Guarantee (SG) provides resources for retirement, on a pre-funded basis, which makes it sustainable. But especially for workers whose pre-retirement income sits in the upper third of the earnings distribution, the SG falls well short of a well-designed retirement income. This is a major challenge for retirement design in Australia. Of the small group of countries relying on pre-funded mechanisms for income-replacement policies, Australia is alone in specifying no drawdown structure. Recent policy discussion concerning retirement income policy suggests that policymakers are aware of this. While much more research is required before we have a comprehensive understanding of this policy area, enough is known to give us a direction for policy reform. Much of the available and relevant evidence is summarised in three requested CEPAR submissions to the Financial Systems Inquiry (CEPAR 2014a, 2014b, 2014c). 
Overall, while many unanswered research questions remain, and there is much policy reform to be undertaken, the directions for retirement income policy reform are becoming clear. My assessment is that, in policy terms, we're ahead of the game compared with most comparable economies. This may be cold comfort-many existing systems are clearly unsustainable, and will likely be subject to arbitrary reductions in benefits into the future, implemented at a time when households are least able to adapt - after their earnings capacity has been depleted. Perhaps the least settled aspect relates to the tax treatment of superannuation, although the blueprint laid out in the 2009 Henry Review (Commonwealth of Australia 2009) provides an excellent starting point.

\section{Health and aged care}

Health and aged care provision is a major challenge even without the additional pressures associated with an ageing demographic. This is not my area of expertise, so I will be briefer. The Intergenerational Report (IGR) (Commonwealth of Australia 2009) suggests that the major source of increases in government health outlays to 2050 will not be population ageing, but technology improvement. Other reports suggest that the most important source of outlay increase will be demographic change. In a way, it doesn't matter. To deliver up-to-date health care to Australians 30 years from now will cost a lot more than it does today, unless something changes.

One possible cost reduction measure is the promotion of e-health. A high proportion of public health outlays is devoted to hospital stays for chronically ill patients, whose acute episodes occasioning hospitalisation may have been avoided with closer monitoring. International evidence on the benefits of remote monitoring (I have in mind monitoring through home-based devices to a central hub that flags indications of acute attacks) is clear. One would think Australia, with its unique challenges around remote communities, would be at the forefront of these initiatives, but this does not appear to be the case. This is an example of infrastructure development for an ageing demographic, which I allude to briefly below, but there is a culture issue as well. Scalable adoption of e-health monitoring requires cultural 
acceptance by both the health professions and their clients, and this may be as formidable a barrier to implementation as the installation of the required technology.

A second aspect of health and aged care worthy of note relates to cognitive decline. With increasingly longevity, the incidence of debilitating cognitive decline, either dementia or simply major dysfunction, will grow, by rates that vary by source, but that are alarming. As Hurd et al. (2013) have demonstrated for the US, the potential costs of Alzheimer's disease into the future are very high. But the costs of generalised cognitive decline may be even higher. To the extent that cognitive capital, to use Kaarin Anstey's term, can be maintained, these costs may be avoided. There is mounting evidence that maintaining workforce attachment is associated with lower rates of cognitive decline, even after self-selection is controlled for. For example, Rohwedder and Willis (2010), using data across countries with substantially different policies regarding retirement age, find that early retirement has a significant negative impact on the cognitive ability of people in their early 60 s that is both quantitatively important and causal. This has implications for policies towards mature labour force participation, discussed later.

In a way, the issue of cognitive decline provides a convenient bridge between health and aged care. Aged care presents enormous challenges: the strain on carers and family relationships, both intraand intergenerational; the work-care dilemma; and the fiscal cost of care.

On a framework for aged care, Australia has made a good start, with a policy stance articulating clear guidelines about the future shaping of policy. Missing is any clear account of funding sources. But for those owning one, it will probably be the owner-occupied home. The high owner-occupier rate among the elderly, combined with high home prices, certainly constitutes serious resources to purchase residential aged care when that becomes necessary, and the home and community emphasis of the new policy should ensure that happens less, and for shorter durations, than is currently the case. Work needs to be done, by academe, both government and business, to develop home equity drawdown instruments that elderly Australians feel comfortable and safe with. But that is doable, and there is some time in which to do it. 


\section{Mature labour force participation}

This is perhaps the greatest challenge, and greatest opportunity in economic, social and familial adjustment to population ageing, and in particular increased longevity. Working for longer is an inevitable consequence of living for longer, yet is resisted by many whose expectations of chronological age of retirement are challenged by this surprising shift in mature life expectancy. Yet many people, even the majority, of those now in their 50s, can expect to live to their 90s. And their healthy lives will extend also. Policies have to be adjusted to reflect this - superannuation access age, worker compensation insurance, and most importantly, attitudes have to change. Age discrimination is increasingly under challenge by regulators and policymakers. Susan Ryan has suggested 'career checks' to see whether a job is conducive to working longer. Relatedly, continuing education should be directed to guiding workers into occupations in later years that they can pursue into their late 60s.

A number of workforce issues will likely arise as demographic change sets in. Diversity in the workplace needs to embrace age diversity as well as gender and ethnic diversity. Little research has been conducted into the impacts of age diversity in the workplace. An improved understanding of the implications of an age-diversified workforce would assist firms in establishing workplace practices to induce an accepting culture. Superannuation entitlements that are linked to final salary need to be changed so that a worker can stay in the workforce at a reduced wage without having his or her benefits reduced. Generally, workers will have to adjust to working longer, in response to longer and healthier lives.

\section{Housing and infrastructure}

If a senior government official had been asked, 50 years ago, to predict the path of future urbanisation in Australia, he would very likely have indicated that the then major centres of Sydney, Melbourne, Brisbane and Perth would be joined by major regional centres. Population growth and urbanisation would take place without extreme agglomeration. Nothing like that has eventuated. Instead, site rents in these four major centres have increased more than wages, and housing affordability has become a major social issue. 
It is unclear why Australia's population has become so concentrated in capital cities. One possibility is that technological innovation has allowed certain cities to become knowledge-intensive, creating new jobs, and that has meant that the best career opportunities are available in those cities (Glaeser and Resseger 2010). But the result is that housing affordability is currently strained, in spite of historically low interest rates.

This is a challenge in political economy. Local interests, represented by political groupings across Australia's fiscal federal structure, severely constrains affordable housing development, and lack of complementary infrastructure exacerbates the problem. It is relevant to the ageing of the population because of its link with intergenerational equity (the baby boomers hold the bulk of housing wealth), and because of its implications for the intragenerational distribution of wealth in future generations. I return to this point below.

\section{Risk and risk management}

Overwhelmingly, our financial services sector is geared to wealth management rather than insurance. At least two major social issuesthe ageing demographic and climate - mean that this will change over the next two decades. This change may not yet be fully appreciated, either by government or private insurers. The impact of climate risk on the financial sector has been explored by Whalley and Yuan (2009). Here we focus on the risks of being older, and the appropriate policy stance to maximise private coverage of the associated risks.

The central point here is that to induce the private sector to accept more retirement risk, government has to develop financial instruments, and design policies and regulations such that these risks can be managed by private institutions. It is often observed that government already bears much longevity risk, for example, and does not wish to extend its exposure. But it should be recognised that the insurer of last resort is always the government-disaster and drought relief is just one example. So by carefully designing the nature of the additional risk it takes on, it can make it attractive for the private sector to insure where no products would be offered in the absence of government covering, for example, tail risk. 


\section{The challenges of population dynamics}

\section{Intergenerational relationships}

Unbalanced demographies can place intergenerational relationships under strain. Because of the nature of intergenerational transfers, and the impossibility of enforcing contracts necessary for the commercial provision of many intergenerational goods, most intergenerational exchange is mediated through family or government. There are enormous benefits to these exchanges, but in the case of governments, they require political will, and in the case of family, they require trust.

Most aged care is still provided by family; much child care is provided by grandparents. Depending on your starting point, existing generations provide environmental protection for future generations, or deplete the environment for future generations. R\&D investment, often subsidised by government, will predominantly benefit future generations, a forward intergenerational good, with benefits flowing to younger generations. Government-funded retirement transfers, such as the Age Pension, are a backwards intergenerational good.

To maintain the institutional basis for these exchanges under demographic shift is challenging. Again, Australia is in a relatively favourable position. Its demographic change is slow and its policies are geared toward considerable self-sufficiency among the older generation.

Nevertheless, caution is required. The current older generations are resource-rich as a whole, but the wealth is unevenly spread. If policies, driven by the fiscal strains of demographic change, are adopted that disadvantage members of the younger generation who do not have access to parental resources, then this could well precipitate an intergenerational tendency toward increased intragenerational inequality. If home purchase cannot be achieved without parental aid, or university education becomes so expensive that only those with family resources will risk the debt, then we have the beginnings of a process where major conduits to wealth and human capital accumulation are denied to a segment of the next generation. This will happen only in the long term, but is all the more invidious for that. And once it has happened, it will be difficult to reverse. 
Along with higher education, housing will likely continue to be a major channel for wealth accumulation for successive generations of Australians. But where in the past access to these conduits to affluence has been available to most, it is possible that in the future it will be accessible only to those with the liquidity to accumulate a substantial deposit. In many cases, these will be the same people as those with family resources behind them.

\section{Tax revenues}

Whatever we do, tax revenue will increase with an ageing demographic, and tax structure will need to be modified to meet the increased revenue requirement as tax bases change with changing population structure. We have a tax system where capital income tax is separated from the labour income tax. Major sources of capital income, the home and superannuation, are effectively taxed under an expenditure tax regime. To me, this is intuitively appealing. While there may be arguments for taxing the returns to both capital and labour income, there is no argument that the tax rates should be the same. Although some capital income taxation may be efficiency-improving, low capital income tax rates make economic sense. I find myself disagreeing with many tax analysts, that the way to increase tax revenue is to close the 'gaps' in the capital income tax base, whether it be the taxation of superannuation, negative gearing, or other capital income targets. This is not to say those tax structures could not be improved. But this is not the way to raise the revenue take.

Two avenues for increasing tax revenue present themselves. First, the GST. Through a broader base and an increased rate, for example 12 per cent, significantly more revenue could be raised. Because government benefits are indexed to prices, people who rely heavily on these as a source of income would be largely protected from the impacts of this tax increase. Low-income workers would be affected, however, as would self-funded retirees. To maintain overall progressivity, the two highest marginal rates in our personal income tax could be increased by two percentage points. This would impact in only a minor way on saving, because the major saving channels are protected from the capital income tax. It would of course impact labour incomes. But most people who earn at these levels of income are motivated by considerations other than disposable income per hour. The labour 
supply impact would be small. Overall, our taxation system, while it could be greatly improved, functions well. It would function just as well, and raise more revenue, with these two adjustments.

\section{International interactions}

At the moment, these are largely unmapped, another research program to be done. Some idea of the range of stage of demographic transition, and speed of adjustment, of our regional neighbours, is given in Figure 2. To see how these might matter, consider the following. China is currently still a young economy, but is ageing rapidly. The demographic dividend is still positive - it is a highly productive country, with relatively few dependants, old or young. In the next 15 to 20 years that will flip. The workforce will decline, and an ever larger cohort of older people will come to rely on what will be largely government pensions. This will likely change expenditure priorities in China. Instead of government spending on infrastructure, it will be spending on transfers that will flow to households. And direct foreign investment from China may decline as well. This will generate changes in the pattern of import demand, impacting Australia's terms of trade and overall welfare, and the shape and scale of our evolving infrastructure.

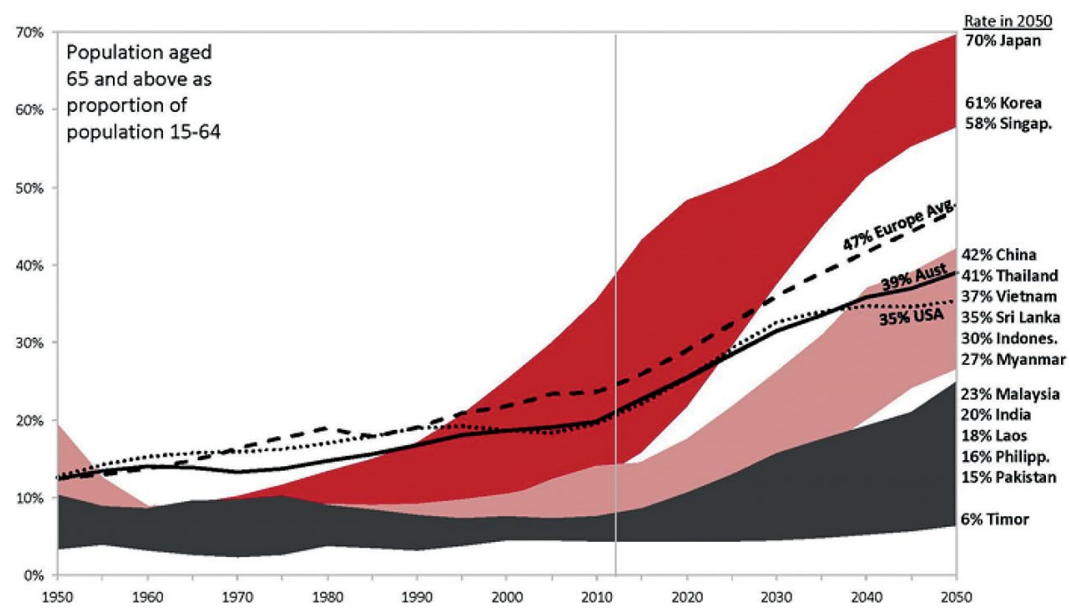

Figure 2. Population ageing: Dependency ratio

Source: Chomik and Piggott (2012). 
Migration patterns will also change. There will likely be fewer migrants from China, more from Indonesia and India. Specific workforce requirements, such as for aged care, may be sourced from other countries, such as the Philippines.

Of course, this is just one scenario, and an oversimplified one at that. But Australia, as a small developed country with strong trade ties to the rapidly ageing and ever larger economies of Asia, will doubtless be affected by the unfolding demographic transition underway there. Surely a national policy challenge.

\section{Acknowledgements}

Financial support from the ARC Centre of Excellence in Population Ageing Research (CEPAR) (CE110001029) is gratefully acknowledged.

\section{References}

CEPAR (2014a). CEPAR Submission to the Financial System Inquiry, 31 March. ARC Centre of Excellence in Population Ageing Research, UNSW Business School, UNSW Australia.

CEPAR (2014b). CEPAR Supplementary Submission to the Financial System Inquiry, 12 June. ARC Centre of Excellence in Population Ageing Research, UNSW Business School, UNSW Australia.

CEPAR (2014c). CEPAR Submission Number 3 to the Financial System Inquiry: Drawdown defaults, 23 August. ARC Centre of Excellence in Population Ageing Research, UNSW Business School, UNSW Australia.

Chomik Rafal and Piggott John (2014). The Australian and United States Retirement Income System: Comparisons with and Lessons for the United States. In Olivia Mitchell and Richard Shea (Eds) Re-imagining Pensions: The next 40 years. Oxford: Oxford University Press, pp. 274-297.

Commonwealth of Australia (2009). Australia's Future Tax System, Report to the Treasurer, December 2009, Part One: Overview. Canberra: Department of Treasury. 
Commonwealth of Australia (2015). 2015 Intergenerational Report: Australia in 2055. Canberra: Department of Treasury, March 2015.

Conesa Juan Carlos, Kitao Sagiri and Krueger Dirk (2009). Taxing Capital? Not a Bad Idea after All! American Economic Review, 99(1): 25-48.

Glaeser Edward and Resseger Matthew (2010). The Complementarity Between Cities and Skills. Journal of Regional Science, 50(1): 221-244.

Hernaes Erik, Markussen Simen, Piggott John and Roed Knut (2016). Pension Reform and Labour Supply, Journal of Economics, 142: 39-55.

Hurd, Michael, Martorell Paco, Delavande Adeline, Mullen Kathleen and Langa Kenneth (2013). Monetary Costs of Dementia in the United States. The New England Journal of Medicine, 368: 1326-1334.

Kumru Cagri and Piggott John (2010). Social Resilience, Meanstesting, and Capital Taxation-Reflections on Economic Paradigms in Towards a More Resilient Society: Lessons from Economic Crises. Report of the Social Resilience Project, October. Japan: The Japan Institute of International Affairs, pp. 45-56.

Piggott John and Whitehouse Edward (2011). Session 3: Paying for the Past, Providing for the Future: Intergenerational Solidarity. Issues Paper, OECD Ministerial Meeting on Social Policy, OECD Conference, Paris, 2-3 May.

Prskawetz Alexia and Sambt Joze (2014). Economic support and the demographic dividend in Europe. Demographic Research, 30(34): 963-1010.

Rice James, Temple Jeromey and McDonald Peter (2014). National Transfer Accounts for Australia: 2003-04 and 2009-10 Detailed Results. ARC Centre of Excellence in Population Ageing Research and Crawford School of Public Policy, The Australian National University. www.cepar.edu.au/media/134354/nta_report_2014.pdf.

Rohwedder Susann and Willis Robert (2010). Mental Retirement. Journal of Economic Perspectives, 24(1): 119-138. 
Sefton James, van de Ven Justin and Weale Martin (2008). Means testing retirement benefits: Fostering equity or discouraging savings? Economic Journal, 188(528): 556-590.

Spijker Joroen and MacInnes John (2013). Population ageing: The timebomb that isn't? BMJ, 347. doi: 10.1136/bmj.f6598.

Whalley John and Yuan Yufei (2009). Global Financial Structure and Climate Change. Journal of Financial Transformation, 25: 161-168.

Yates Judith and Bradbury Bruce (2010). Home ownership as a (crumbling) fourth pillar of social insurance in Australia. Journal of Housing and the Built Environment, (25)2: 193-211. 
This text is taken from Population Ageing and Australia's Future, edited by Hal Kendig, Peter McDonald and John Piggott, published 2016 by ANU Press, The Australian National University, Canberra, Australia. 